\title{
External Motivation and Organizational Commitment at Educational Institution Employees
}

\author{
Dr. Ortenca Kotherja \\ Msc. Brunilda Kotherja \\ Lecturer at the University of Educational Sciences, Elbasan \\ Email: kotherja_ortenca@hotmail.com
}

\author{
Doi:10.5901/ajis.2016.v5n3s1p218
}

\begin{abstract}
The school institution is the basis of education of younger generations. For this reason, academic services and educational institutions should be characterized by the professionalism of the staff and motivated. Companies/institutions are looking for more efficient ways to increase their productivity. Organizational commitment predicts many positive behaviors in the workplace, such as increased performance, productivity and efficiency. Due to this fact there is a growing interest to understand the relationship between motivation and commitment. Despite many researches on motivation and organizational commitment, the relations between different forms of motivation and organizational commitment in Albania have been studied very little. The aim of this study is to conduct research on the relationship between external motivation and organizational commitment. In this research is used the quantitative scientific research method. For data collection were used two questionnaires "Work Motivation Questionnaire" and the "Organizational Commitment Questionnaire". In the end of this article are some of the result which shows a connection between motivation and commitment organizational and the importance of them in the development of student.
\end{abstract}

Keywords: organizational commitment, work motivation

\section{Introduction}

The rapid development has caused many companies and institutions to work harder by increasing the productivity and quality of products and services they provide. The term motivation is typically defined as an emotion, wish, need or impulse that acts in order to encourage the actions. It is something that comes internally but at the same time people are motivated by external urges, but this doesn't contradict the idea that the motivational basis of an individual comes internally. The economy is changing too fast in today's society; competition worldwide continues to significantly grow. To increase the productivity, it is important to stimulate employees' skills George. J.M \& Jones, G.R. (2008). Thus the performance and productivity at work are typically determined by the motivation to work hard and high motivation means greater efforts and higher productivity Mathieu, J.E. \& Zajac, D.M. (1990). Thus, we may say that motivation is the factor that pushes the employees to improve their performance and increase productivity Mitchell, T. R., \& Daniels, D. (2003). To engage employees at work has a great importance on which affect a series of internal and external factors. Crucial element to enhance work performance is employees' engagement Tung, L. R. 1981. Regarding this, researchers Brehm and Self (1989) have pointed out the importance of motivating factors, the size and intensity of motivation, where every internal or external motivating factor affects the level of motivation pleasure and it will affect directly in increasing its level. Motivation is defined as a process that consists of the direction, intensity and persistence of the individual to achieve a goal. Motivational process usually begins when someone recognizes an unsatisfied need. Afterwards a goal is set to be achieved and to satisfy the unmet need.

The purpose of this article is to contribute in terms of knowledge and provide a clear picture on motivation and external motivational factors and show the impact of educational institution employees on work commitment.

The objectives of this study are:

* To provide knowledge on motivation, external motivating factors and organizational commitment at work.

* To show the role of motivating factors and organizational commitment on educational institution employees.

* To show the dependence of teachers' motivation in teaching regarding organizational commitment

* To show the impact of socio-demographic factors on motivation and commitment at work of the employees.

This study was conceived to be realized based on some research questions as following: 
- What is the relationship between motivation and organizational commitment at work?

- What is the relationship between external motivation and organizational commitment?

- Which is the impact of demographic factors (age, sex, year of work) in the external motivation of employees?

- Which is the impact of demographic factors (age, sex, year of work) to employees in organizational commitment?

\section{Motivation and Its External Factors}

Motivation is the driving force, encouraging the direct impact on productivity, the quality of the organization / institution.

Motivation in work is related to a set of factors that determine the behavior within the organization, the form, direction, intensity and duration of it. Understanding what motivates employees is the focus of many studies in the field of organizational psychology. Motivation can often be used as a tool to predict the behavior of individuals in the workplace varies between individuals and in combination with skills and environmental factors affects the behavior and performance of employees. Because motivation in the workplace has an important role in the behavior and performance of employees, it is the key for organizations to understand work environments, so as to encourage positive behaviors and discourage those that are not positive. Understanding what motivates employees is the focus of many studies in the field of organizational psychology. Motivation can often be used as a tool to predict the behavior of individuals in the workplace, and it greatly varies between individuals and in combination with skills and environmental factors affects the behavior and performance of employees. Thus, organizations that are able to implement evaluation systems establish reward mechanisms and find ways to negotiate between career goals and needs of company employees. While organizations which fail to notice the implications of employee motivation, experience a reduction in production and productivity followed by a loss of personnel, increased development costs and missing schedules.

Motivation is an issue that is influenced by many factors. No factor can guarantee motivation in the absence of other factors. It consists of two types of motivation; internal and external motivation. Regarding external motivation researcher has claimed that it is "the desire to expand efforts to get results outside of work such as bonuses or recognition" (Grant, 2008 f.49). External motivation is related to external stimuli such as salaries, bonuses and other kinds of tangible rewards

\section{Theoretical Approaches about Organizational Commitment}

Organizational commitment of employees is an important phenomenon to achieve their performance in the places they work. A significant provider of their commitment is motivation which allows employees to spend energy, time in the organization / institution where they work. Studying this phenomenon along with motivation and performance is very important due to the fact that it is an important indicator element which indicates the desire, effectiveness, productivity at work, of employees and whole organization. Commitment basis includes those factors that are believed to contribute in the development of employee engagement. The basics of the different forms of engagement are similar regardless of engagement objective Meyer, J.P. \& Herscovitch, L. (2001). Thus, the same bases are applied for the development of commitment to social focus and goals. However this does not mean that the specific conditions of previous events will be the same or the commitment nature of a goal will necessarily be the same as the engagement nature of social focus.

For example, employees may have a strong emotional commitment towards organization, because the company culture is in accordance with their personal values. However, their emotional commitment to a specific goal set by the organization (e.g., by reducing the length of service calls) may be weak, if they believe that the achievement is not in the best interest of the company.

\section{Motivation and Organizational Commitment}

Motivation works as a significant provider of employees' engagement to spend time and energy to the organization in which they are employed ( Mowday, Steers and Porter, 1979). Due to this fact, there is a growing interest in understanding the relationship between motivation and organizational commitment. One of the main benefits of including engagement within the model of motivation is that it helps identifying the mediation mechanisms explaining employee relations focuses on social behavior.

The results showed that professional development and rewards were positively connected with teachers' commitment. Also the motivation types affect employees' work commitment. 


\section{Methodology}

The study was conducted in 4 schools in Elbasan. The participants' selection was conducted randomly being of different genders, ages and schools making the sample as much representative as possible. Schools participating in the study were in the urban area, 180 questionnaires were distributed. Participation in the study was voluntary and completely confidential. Regarding these issues, participants were informed before being included in the study. Once participants said they were willing to be involved in the study they completed two questionnaires. One of the questionnaires based on the measurement of motivation and the other based on the measurement of organizational commitment. The final sample with which they began the analysis was $N=120$. In this sample $(N=68)$ were female and $(N=52)$ were male. The average age of participants ranged from 18 to 56 years, with annual average growth rate 1.94 and standard deviation $(S D)=0.79$. Their work experience ranged from 6 months to 10 years with an average of 2.69 and $(D S)=1: 09$

\subsection{Sample description}

Population of this study are full-time teachers in public school system including elementary school teachers (1-6), teachers of lower secondary education, classes $6-9$, and teachers of upper secondary education, classes 10-12, in the city of Elbasan. In this study, the main criteria of including teachers in the sample was for them to be pre-university teachers of the public school system employed full time and as exclusive criteria was excluding private school teachers.

Instrument: In this study is used "Members of Motivation at Work" by Robert P. Bradly (2011), taken in a scientific journal. The revised instrument is developed by the author and is used in several studies in which has been explored employees' motivation at work. This instrument was taken from an internet site which was an open source and allowed the use of the instrument. Based on these dimensions division there are formed 2 subscales: internal and external motivation. For this study we have taken the subscale that measures the external motivation.

For the organizational commitment measurement, was used the Organizational Work Commitment questionnaire, which gives data regarding teacher engagement in the learning process by giving their approval to statements such as: I would be very / happy to spend the rest of my career in this institution, I owe much to my institution, or I don't feel like "part of the family" in my institution etc. Assertions are coded answers in a way, where higher scores reflect the high employee engagement in the organization in which they work and lower results reflect a low employee commitment to the organization. Some of the statements are eliminated in order to avoid the same answer. Questions in this section are again measured by Likert scale (1- least agree to 5 - totally agree).

\subsection{Reliability}

Reliability analysis was used to test the reliability of the data. Reliability indicates the stability of the measurement. The reliability analysis was conducted for two questionnaire and eight dimensions of the Motivation at Work questionnaire. The value of the reliability coefficient (alpha) or Cronbach's alpha for the Motivation at Work instrument resulted 0.82 and for the Organizational Engagement instrument resulted 0.85 .

\subsection{Statistical analysis of data}

Part of this process was making a database with the collected data and their processing and analysis. Processing and analysis was conducted through computer software packages SPSS 17.0 and Excel.

Data analysis was performed through descriptive analysis, the tables cross (Cross tabulations), tests of independence, correlates between variables, factorial analysis, constructing and reviewing the objectives and research questions placed on the study, analysis of variance (ANOVA), construction of multiple regression equation etc. So study on data analysis contains not only a descriptive analysis but also an analytical analysis.

\section{The Result of Study}

The aim of this study is to describe and analyze motivation, motivating factors by grouping these recent and external and internal needs, as well as connection to organizational commitment of the teachers in the educational institution of preuniversity system in the public educational institutions in Elbasan.

Number one objective results- To see the relationship between motivation and organizational commitment of 
teachers in the institution

To examine the relationships that exist between the measured variables in this study Hypotheses Co relational analysis was conducted between motivation and organizational commitment of employees of the school. The data below shows that between Motivation and Organizational Commitment was a positive correlation and that there was a statistically significant relationship but we can say that this relationship was not very strong, which resulted Pearson correlation $r=0: 23$.

Table 1. Correlations between Motivation and Organizational Commitment

\begin{tabular}{|l|l|c|c|}
\hline \multicolumn{2}{|c|}{} & $\begin{array}{c}\text { Organisational } \\
\text { commitment }\end{array}$ & Motivation \\
\hline \multirow{2}{*}{$\begin{array}{l}\text { Organisational } \\
\text { commitment }\end{array}$} & Pearson Correlation & 1 & $.234\left(^{*}\right)$ \\
\cline { 2 - 4 } & Sig. (2-tailed) & & .010 \\
\cline { 2 - 4 } & $\mathrm{N}$ & 120 & 120 \\
\hline \multirow{3}{*}{ Motivation } & Pearson Correlation & $.234\left(^{*}\right)$ & 1 \\
\cline { 2 - 4 } & Sig. (2-tailed) & .010 & 120 \\
\cline { 2 - 4 } & $\mathrm{N}$ & 120 & \\
\hline
\end{tabular}

Table 2. The relationship between external motivation and organizational commitment

\begin{tabular}{|l|l|c|c|}
\hline \multicolumn{2}{|l|}{} & $\begin{array}{c}\text { Organisational } \\
\text { commitment }\end{array}$ & External motivation \\
\hline \multirow{2}{*}{$\begin{array}{l}\text { Organisational } \\
\text { commitment }\end{array}$} & Pearson Correlation & 1 & .132 \\
\cline { 2 - 4 } & Sig. (2-tailed) & & .150 \\
\cline { 2 - 4 } & $\mathrm{N}$ & 120 & 120 \\
\hline \multirow{3}{*}{ External motivation } & Pearson Correlation & .132 & 1 \\
\cline { 2 - 4 } & Sig. (2-tailed) & .150 & 120 \\
\cline { 2 - 4 } & $\mathrm{N}$ & 120 & \\
\hline
\end{tabular}

Number two objective results - Regarding the relationship that exists between internal and organizational commitment. In order to answer this objective and research question, based on the engagement dependence with types of motivation was used Pearson correlation. The table above shows that we have a Correlation relationship between organizational commitment and external motivation. We see that external motivation has not a strong statistical bond with organizational commitment but is important to say that there is a connection between them.

\subsection{T-test analysis}

To see if there are gender differences between men and women at the level of motivation and organizational commitment took the T-test analysis. Through t-test was specifically examined the variables relationship between female and male employees.

Table 3. Averages, $\mathrm{F}$ and $\mathrm{t}$ for men and women regarding the level of motivation

\begin{tabular}{|c|c|c|c|c|c|c|c|}
\hline & & Average & Standard deviation & Scale of freedom & $\mathrm{t}$ & $\mathrm{F}$ & $\mathrm{P}$ \\
\hline Gender & Women & 56.67 & 6.089 & 88 & -0.86 & 3.38 & 0.37 \\
\hline & Man & 57.69 & & & & & \\
\hline
\end{tabular}

From t-test analysis results that there is no statistically significant difference between women and men in work motivation. T-test resulted statistically insignificant $t=(88)=-0.86, p<0.05$, which means that female workers have the same level of motivation (average $=56.67, s=6: 08$ ) as male workers (average $=57.69, s=5.86$ ). Despite of the change which resulted in the descriptive data (they proved that women had a higher level of motivation than that of men in percentage) this difference is not statistically significant

Table 4. Averages, $\mathrm{F}$ and $\mathrm{t}$ for men and women regarding organizational commitment level

\begin{tabular}{|l|l|l|l|l|l|l|c|}
\hline & & Average & Standard deviation & Degrees of freedom & t & F & P \\
\hline Gender & Women & 56.61 & 8.80 & 118 & -1.88 & 1.068 & 0.062 \\
\hline & Man & 59.92 & 10.35 & & & & \\
\hline
\end{tabular}


From t-test analysis results that there is no statistically significant gender differences between men and women at the level of organizational commitment at work. T-test results us statistically insignificant t $(118)=-1.88, p<0.05$, which means that female employees have the same level of organizational commitment (average $=56.61, s=8.80$ ) as male workers (average $=59.92, s=10: 35$ ). Despite the change which resulted in the descriptive data (women were those who had organizational commitment at higher levels than males), this difference is not statistically significant

\section{Discussions}

The aim of this study was to study the phenomenon of motivation and organizational commitment at educational institution employees' in the public schools of Elbasan city. "After collecting the needed data, the research and study questions were tested, the results were concluded and according to them were developed the discussions and recommendations. Below we will discuss the results of the study, will present the strong and weak points of the study, and in the end will be given recommendations. The results show that the major part of employees feel motivated at a moderate level in the institution in which they work with a value of $89.2 \%$ and $10.8 \%$ of them said they had a high motivation and none of the employees resulted with a low level of motivation.

Another phenomenon over which was investigated in this study, organizational engagement, also resulted to be prevalent among employees of the institution at a moderate level $78.3 \%, 5 \%$ of employees resulted that had a low level of organizational commitment, and $16.7 \%$ have a high level of organizational commitment. From the results obtained we can say that the employees of this institution are committed towards the institution, they have a strong desire to remain a member of this organization, have a sense of loyalty to the workplace and identify with the values and goals of the organization in they work. These results are positive for the institution.

\subsection{Discussion regarding research questions}

Research Question No.2 - What is the connection that exists between motivation and organizational commitment? From correlation analysis was found that between motivation and organizational commitment, the correlation was positive and statistically important, a result which is consistent with the findings of Warsi, Fatima and Sahibzada (2009) which in their study stated that motivation at work is a power strongly connected with organizational commitment among employees in the private sector of Pakistan. The relationship between motivation and organizational commitment resulted statistically insignificant where $r=0: 23$. These results conclude that between motivation and organizational commitment there isn't a strong bond statistically, which means that higher results of employees' motivation will not necessarily bring higher results in organizational commitment and conversely.

Results of a study conducted in Iran by researcher Alimohammadi and Jamali, (2013) showed that motivation at work has a significant positive impact upon organizational commitment of employees. The results of this research question, the difference between the foreign literature and Albanian context, it may be due to various causes. Motivation may not be significant predictor of organizational commitment and vice versa due to limited labor market in Albania. The high rate of unemployment in our country causes the employees to get engaged in their work place showing effort and loyalty by not risking the loss of their job. Being that workplaces are limited and labor market doesn't offer many opportunities for employees to engage in the organization they work, even if they do not sufficiently motivated by motivating the organization's policies.

Research Question No.2 - What is the relationship that exists between external motivation and organizational commitment?

From co relational analysis the resulted data were that external motivation has a positive relationship with organizational commitment, but the two variables don't have any significant statistic bond with each other, where $r=0: 15$. From the results of this relationship can say that external motivation is not a strong predictor of organizational commitment and conversely. This result may be due to the fact that is shown from various studies that externally motivated employees when their organization does not offer exterior financial rewards, they tend leave this organization towards another one which offers higher rewards, showing low levels of loyalty to the organization. External motivation is not enough to keep an employee as a part of the organization. When someone is externally motivated, they are focused only on the rewards and not on work itself, the work for them is good enough just to get the reward "(Thomas, 2000, $p$. 131).

Research Question No.3 - Which is the relationship that exists between demographic variables (age, sex, years of work) and motivation? 
From the conducted analysis, the received data from the employees who were part of the study resulted that there was a difference between the level of motivation and gender. They proved that women had a higher level of motivation than men expressed in percentage. God in his research (2006) found that there is significant difference in the level of motivational factors at work between young workers and older ones in the United States. The level of motivation also differed with age of respondents. The collected data showed that people from 29-39 years, were the age group with the highest level of motivation compared to other age groups of employees who were part of the study. This result can be caused by various factors. One of the reasons is that young employees are more motivated to develop professionally in the workplace and to grow in their career.

Research Question No.4 - The relationship that exists between demographic variables (age, sex, years of work) and organizational engagement?

From the analysis resulted that women were the ones who had higher levels of organizational commitment than men. This results show that women put more effort, loyalty and support the values of their organization more compared to men. This result can come for various reasons. One of these reasons is the fact that women have always been considered as responsible, are those that are committed in the family, in society and it can also affect their commitment in their workplace.

Regarding the relation between age and organizational commitment, resulted that the age group which has a higher level of organizational commitment is the age group 29-39 years compared to other age groups. The explanation of this result may be that high commitment towards the institution, in this case a school, will reward them by professionally growing.

\section{Conclusions and Recommendations}

Results of this research will form an opportunity for other researchers to further investigate the influence of motivation in organizational commitment. It is important for leaders of the institution to provide a suitable environment to positively reinforce employees' commitment. As resulted from this study, but even from previous studies, organizational motivation and commitment are positively correlated with each other. Organizations / institutions should enhance to increase positive relationship between these two variables, to achieve a positive effect on organizational commitment.

Ways to improve work motivation and organizational commitment can change the nature of work, organizations and from one person to another. Commitment increase will increase efficiency and will bring higher results which every organization wants.

To have engaged employees, it is important to get information about the motives of employees by developing functional conversations with them regarding motivational factors that can motivate them to do their job. When managers have a clear picture about the motivation of their employees, this information can serve in making decisions about the management of human resources. The ways to work with each of the employees would be more effective if they are based on factors which will affect the motivation of each of them.

Human resources department and managers of this institution should be very cautious and integrate their policies and external motivational factors.

Referring to these conclusions organizations should tend towards employees who contribute to others because it shows that employees are not only concerned about them, but are interested in other people and the organization in which they work.

Another aspect that the leaders of the institution should pay attention to is the training and development of employees. The institution must provide continuous trainings for its employees.

\section{References}

Alimohamaddi \& Neyshabor (2013). International Journal of Research in Organizational Behavior and Human Resource Management, Vol. 1, No.3, pp. 1-12

Brehm J.W \& Self E.(1989) A "The Intensity of Motivation " Ann. Rev. Psychol. 1989. Fq.110

Castle. P, dhe Buckler.S, (2013) "How to be a Successful Teacher: Strategies for Personal and Professional Development,

George, J. M. \& Jones, G.R. (2008). Understanding and Managing Organizational Behavior. New Jersey:Pearson Apprentice Hall

Grant, A., \& Singh, J. (2011). "The problem with financial incentives -- and What to do about it." Knowledge @ Wharton,

Meyer, J.P., Becker, T.E. \& Vandenberghe, C. (2004). Employee Commitment and Motivation: a

conceptual Analysis and Integrative Model. Journal of Applied Psychology, 89, 991-1007.

Meyer, J.P. \& Herscovitch, L. (2001). Commitment in the workplace: Toward a general model. Human Resource Management Review, 11, 299-326. 
Mathieu, J.E. \& Zajac, D.M. (1990). A Review and Meta-Analysis of the Antecedents, Correlates, and Consequences of Organizational Commitment. Psychological Bulletin, 108, 171-194.

Mowday, R. T., Porter, L. W., \& Steers, R. M. (1982). Organizational linkages: The psychology of commitment, absenteeism, and turnover.San Diego, CA: Academic Press

Mitchell, T. R., \& Daniels, D. (2003). Motivation. Handbook of Psychology, Vol. 12. Industrial Organizational Psychology, ed. W.C. Borman, D.R. Ilgen, R.J. Klimoski, pp. 225-54. New York: Wiley.

Tung, L. R. 1981. 'Patterns of Motivation in Chinese Industrial Enterprises', The Academy of Management Review, vol. 6, no. 3, pp. 481489.

Thomas, K.W., \& Velthouse, B. A. (1990). Cognitive elements of empowerment: An "interpretive" model of intrinsic task motivation. Academy of Management Review, 15, 666-681.

Warsi, S. Fatima,N., \& Sahibzada, S. A. (2009). Study on relationship between organizational commitment and its determinants among private sector employees of Pakistan. International Review of Business Research Papers, 5(3), 399-410. 